\title{
Manifestações Cutâneas em Doentes com COVID-19
}

\section{Cutaneous Manifestations in COVID-19 Patients}

\author{
Pedro Mendes-Bastos ${ }^{1}$
}

\section{INTRODUÇÃO}

A pandemia da COVID-19 (coronavirus disease 19), infeção causada pelo coronavírus SARS-CoV-2 (severe acute respiratory syndrome coronavirus 2), veio mudar o paradigma da medicina de uma forma global neste início de século. ${ }^{1}$ Acredita-se que a porta de entrada à maquinaria intracelular humana é fundamentalmente o recetor ACE-2 (angiotensin converting enzime 2), expresso em vários tecidos, mas maioritariamente nas células do epitélio respiratório. ${ }^{2}$

Os dermatologistas estiveram na linha da frente do conhecimento médico numa das grandes pandemias do século $X X$, tendo sido pioneiros no reconhecimento e a caracterização das manifestações cutâneas da infeção pelo $\mathrm{VIH}{ }^{3}$ Mais uma vez, dada a acessibilidade e a rele- vância clínica das manifestações cutâneas para qualquer doença, a Dermatologia é mais uma vez uma especialidade chave nesta nova infeção viral. Tal como em muitas outras infeções virais, os doentes com COVID-19 apresentam em qualquer idade sintomatologia cutânea que tem ganho a atenção da comunidade científica nos últimos meses. ${ }^{4}$ Até ao presente momento, não foram descritos achados dermatopatológicos específicos da COVID-19 em doentes autopsiados, pese embora uma grande miríade de dermatoses não específicas já tenha sido descrita nestes doentes. ${ }^{5}$

\section{DESCRIÇÃO}

Nas primeiras semanas da pandemia, surgiram na literatura científica algumas descrições de manifestações 
cutâneas em doentes com COVID-19 que careciam de fotografias clínicas de qualidade e de caracterização histopatológica. Ainda assim, autores provenientes de diferentes partes do mundo foram publicando casos, documentando manifestações cutâneas em doentes com infeção confirmada laboratorialmente., 6,7 Passados alguns meses desde o início da pandemia, o panorama mudou substancialmente havendo mais e melhor documentação sobre este tema. $\bigcirc$ presente manuscrito pretende sistematizar as manifestações cutâneas mais relevantes descritas na literatura científica em doentes infetados pelo SARS-CoV-2 até maio de 2020.

\section{LESÕES SEMELHANTES A PERNIOSE NOS DEDOS DAS MÃOS E DOS PÉS}

As lesões semelhantes a perniose (ou "frieiras") têm sido descritas de forma frequente em crianças e adolescentes., Clinicamente caracterizam-se como máculas eritemato-violáceas ou acastanhadas em localizações acrais, tipicamente dedos das mãos ou dedos dos pés, podendo coexistir com edema, necrose cutânea punctiforme e mesmo bolhas hemorrágicas. De uma forma geral, são pouco sintomáticas, com dor ou prurido ligeiros em alguns doentes. ${ }^{9}$ O prognóstico é favorável, com resolução completa na maioria dos casos. ${ }^{10,11}$ Alguns autores especulam sobre a relação temporal entre a infeção e o surgimento das lesões (paralela? Pós-COVID?) e inclusivamente sobre a especificidade desta manifestação. Aparentemente, tem havido um elevado número de casos de lesões semelhantes a perniose para a época do ano, e em alguns relatos de casos apenas foi possível confirmar o diagnóstico da COVID-19 em poucos destes doentes, levando alguns autores a possivelmente atribuir este excesso de casos ao confinamento e menor mobilização e não propriamente à infeção. 9,12,13 Este quadro clínico parece surgir em doentes jovens com COVID-19 ligeira e com bom prognóstico. ${ }^{14}$

\section{ISQUÉMIA ACRAL}

Quadros de infeção grave pelo SARS-CoV-2 podem caraterizar-se por um estado de hipercoagulabilidade, com achados laboratoriais de elevação de D-dímeros, fibrinogénio e produtos de degradação de fibrinogénio. Estes doentes críticos podem apresentar isquémia acral, com cianose dos dedos das mãos e pés, bem como gangrena seca e bolhas. ${ }^{15-17}$ Todos os casos descritos com estas manifestações extremas surgiram em doentes com manifestações pulmonares graves de COVID-19.

\section{DERMATOSE PETEQUIAL OU PURPÚRICA}

Têm sido reportados alguns casos de petéquias ou máculas purpúricas disseminadas em doentes com COVID-19, havendo casos com e sem vasculopatia trombótica documentada. ${ }^{18-20}$ Globalmente, a dermatose petequial/purpúrica parece ser um sinal de $\mathrm{CO}$ VID-19 ligeira e com prognóstico favorável, classicamente sem atingimento de mucosas ou palmo-plantar. ${ }^{14}$ Dada a existência de recetores ACE-2 no endotélio vascular, especula-se sobre a possível invasão direta destas células pelo vírus, embora até ao momento tenha sido escassamente documentada a presença de vírus ativo em células endoteliais. ${ }^{2}$

\section{DERMATOSE VESICULAR}

A presença de vesículas disseminadas foi descrita num relato de casos em Espanha. Os autores, dermatologistas, caraterizaram a dermatose como sendo monomorfa, observando-se vesículas predominantemente no tronco, semelhantes às presentes em infeções herpéticas como a varicela. ${ }^{15}$

\section{URTICÁRIA AGUDA}

A urticária aguda é uma dermatose reativa com duração inferior a 6 semanas, caracterizada clinicamente por prurido e pápulas e/ou placas eritematosas e edematosas evanescentes, com ou sem angioedema, que surge de forma frequente no contexto de infeções virais. ${ }^{19}$

É, portanto, natural que se tenham observado vários casos de urticária aguda, habitualmente como manifestação inicial da infeção pelo SARS-CoV-2. ${ }^{14,20-24}$ A presença de urticária aguda em doente com febre é altamente suspeita de etiologia viral e, no contexto pandémico, poderá indiciar COVID-19. ${ }^{14}$

\section{EXANTEMA MACULOPAPULAR OU MORBILIFORME}

Os exantemas maculopapulares são também manifestações cutâneas frequentes das infeções virais, envolvendo mais habitualmente o tronco e a raiz dos membros e poupando a face e as extremidades. ${ }^{19}$ A maioria dos casos descritos ocorreu em doentes adultos, resolvendo em alguns dias. ${ }^{17,25-28}$ Alguns autores especulam sob re a sua associação a prognóstico mais reservado pela COVID-19. ${ }^{14}$

\section{PITIRÍASE ROSADA}

A pitiríase rosada é uma dermatose eritematodescamativa muito frequente em crianças, adolescentes e adultos jovens, especulando-se sobre a sua relação com infeções virais. ${ }^{19}$ Existem também casos publicados de pitiríase rosada em doentes com COVID-19.29,30

\section{DOENÇA DE KAWASAKI}

A doença de Kawasaki é uma vasculite de médios vasos e a primeira causa de cardiopatia adquirida em idade pediátrica. $\bigcirc$ diagnóstico é estabelecido com base em alguns critérios clínicos, sendo vários deles dermatoló- 
gicos, nomeadamente alterações mucosas (como queilite, "língua em morango", eritema difuso da mucosa oral, fissuração dos lábios), dermatose polimorfa (maculopapular, eritrodérmica, urticariforme, semelhante a eritema multiforme) e alterações acrais (como eritema e edema das mãos e/ou pés bem como descamação periungueal). ${ }^{19}$

A etiologia da doença de Kawasaki está ainda mal elucidada, admitindo-se uma relação causal com infeção por vários vírus como adenovírus, enterovírus, rinovírus ou coronavírus. ${ }^{31}$ Após a publicação de Verdoni et al alertando para um aumento do número de diagnósticos desta entidade em Bérgamo no decorrer do pico pandémico, a comunidade internacional focou a sua atenção na possível relação entre a infeção por SARS-CoV-2 e a doença de Kawasaki. ${ }^{32}$ Entretanto, outros casos têm sido publicados, reforçando a relação entre a COVID-19 e uma síndrome semelhante à de Kawasaki. ${ }^{33-35}$ Dado a potencial gravidade e sequelas decorrentes da doença de Kawasaki, o diagnóstico atempado e início rápido de terapêutica apropriada é crucial, sendo a suspeita clínica e o exame dermatológico essenciais.

\section{OUTROS}

Na literatura, outras manifestações cutâneas em doentes com COVID-19 têm sido publicadas, enumerando-se como exemplos o eritema multiforme ou o livedo. ${ }^{15,33,36-38}$

\section{CONCLUSÃO}

As manifestações cutâneas descritas em doentes com COVID-19 são variadas e clinicamente polimorfas. 0 seu reconhecimento atempado reveste-se de elevado interesse para o clínico dada a frequência elevada de doentes assintomáticos ou pauci-sintomáticos, permitindo o diagnóstico precoce e adequado isolamento social. A abordagem multidisciplinar deve ser privilegiada nestes casos, sendo naturalmente o dermatologista o médico mais preparado para a correta avaliação do doente com manifestações cutâneas.

\section{RESPONSABILIDADES ÉTICAS}

CONFLITOS DE INTERESSE: Os autores declaram não possuir conflitos de interesse.

SUPORTE FINANCEIRO: O presente trabalho não foi suportado por nenhum subsídio ou bolsa.

PROVENIÊNCIA E REVISÃO POR PARES: Não comissionado; revisão externa por pares.

\section{ETHICAL DISCLOSURES}

CONFLICTS OF INTEREST: The authors have no conflicts of interest to declare.

FINANCING SUPPORT: This work has not received any contribution, grant or scholarship.

PROVENANCE AND PEER REVIEW: Not commissioned; externally peer reviewed.

\section{REFERÊNCIAS}

1. Zhu N, Zhang D, Wang W, Li X, Yang B, Song J, et al. A novel coronavirus from patients with pneumonia in China, 2019. N Engl J Med. 2020;382:727-33. doi: 10.1056/NEJMoa2001017.

2. Li MY, Li L, Zhang Y, Wang XS. Expression of the SARS-CoV-2 cell receptor gene ACE2 in a wide variety of human tissues. Infect Dis Poverty. 2020;9:45.

3. Friedman-Kien AE. Disseminated Kaposi's sarcoma syndrome in young homosexual men. J Am Acad Dermatol. 1981;5:46871.

4. Sachdeva M, Gianotti R, Shah M, Lucia B, Tosi D, Veraldi S, et al. Cutaneous manifestations of COVID-19: Report of three cases and a review of literature [. J Dermatol Sci. 2020 (in press). doi:10.1016/j.jdermsci.2020.04.011.

5. Recalcati S. Cutaneous manifestations in COVID-19: a first perspective. J Eur Acad Dermatol Venereol. 2020;34:e212-e213. doi:10.1111/jdv.16387.

6. Joob B, Wiwanitkit V. COVID-19 can present with a rash and be mistaken for dengue. J Am Acad Dermatol. 2020;82:e177. doi:10.1016/j.jaad.2020.03.036.

7. Alramthan A, Aldaraji W. Two cases of COVID-19 presenting with a clinical picture resembling chilblains: first report from the Middle East. Clin Exp Dermatol. 2020 (in press). doi:10.1111/ced.14243.

8. Andina D, Noguera-Morel L, Bascuas-Arribas M, et al. Chilblains in children in the setting of COVID-19 pandemic. Pediatr Dermatol. 2020 (in press). doi:10.1111/pde.14215.

9. Duong TA, Velter C, Rybojad M, Comte C, Bagot M, Sulimovic L,et al. Did Whatsapp ${ }^{\circledR}$ reveal a new cutaneous COVID-19 manifestation? J Eur Acad Dermatol Venereol. 2020 (in press). doi:10.1111/jdv.16534.

10. Garcia-Lara G, Linares-González L, Ródenas-Herranz T, Ruiz-Villaverde R. Chilblain-like lesions in pediatrics dermatological outpatients during the COVID-19 outbreak. Dermatol Ther. 2020 (in press). doi:10.1111/dth.13516.

11. López-Robles J, de la Hera I, Pardo J, Martínez J, Cutillas-Marco E. Chilblain-like lesions: a case series of 41 patients during the COVID-19 pandemic. Clin Exp Dermatol. 2020 (in press). doi:10.1111/ced.14275.

12. Abril-Pérez C, Sánchez-Arráez J, Roca-Ginés J, Torres-Navarro I. Perniosis del confinamiento, una vieja conocida en el contexto del COVID-19. An Pediatr. 2020; (in press). doi:10.1016/j. anpedi.2020.04.017.

13. Romaní J, Baselga E, Mitjà O, Riera-Martí N, Garbayo P, Vicente A, et al. Chilblain and Acral Purpuric Lesions in Spain during Covid Confinement: Retrospective Analysis of 12 Cases. Actas Dermosifiliogr. (in press). doi:10.1016/j.ad.2020.04.002.

14. Wollina U, Karadağ AS, Rowland-Payne C, Chiriac A, Lotti T. Cutaneous Signs in COVID-19 Patients: A. Dermatol Ther. 2020 (in press). doi:10.1111/dth.13549. 
15. Galván Casas C, Català A, Carretero Hernández G, Rodríguez-Jiménez P, Fernández-Nieto D, Rodríguez-Villa Lario A, et al. Classification of the cutaneous manifestations of COVID-19: a rapid prospective nationwide consensus study in Spain with 375 cases. Br J Dermatol. 2020;10.1111/bjd.19163. doi:10.1111/bjd.19163.

16. Avellana Moreno R, Villa E, Avellana Moreno V, Estela Villa C, Aparicio M, Fontanella A. Cutaneous manifestation of COVID-19 in images: A case report. J Eur Acad Dermatol Venereol. 2020 (in press). doi: 10.1111/jdv.16531.

17. Diaz-Guimaraens B, Dominguez-Santas M, Suarez-Valle A, Suarez-Valle A, Pindado-Ortega C, Selda-Enriquez G, Bea-Ardebol $S$ et al. Petechial skin rash associated with severe acute respiratory syndrome coronavirus 2 infection. JAMA Dermatol. 2020 (in press). doi:10.1001/jamadermatol.2020.1741.

18. Magro C, Mulvey JJ, Berlin D, Nuovo G, Salvatore S, Harp J, et al. Complement associated microvascular injury and thrombosis in the pathogenesis of severe COVID-19 infection: a report of five. Transl Res. 2020;S1931-5244(20)30070-0. doi:10.1016/j.trsl.2020.04.007.

19. Bolognia JL, Schaffer JV, Cerroni L. Dermatology.4th ed.Amsterdam: Elsevier; 2018.

20.van Damme C, Berlingin E, Saussez S, Accaputo O. Acute urticaria with pyrexia as the first manifestations of a COVID-19 infection. J Eur Acad Dermatol Venereol. 2020 (in press). doi: 10.1111/jdv.16523. doi:10.1111/jdv.16523.

21. Fernandez-Nieto D, Ortega-Quijano D, Segurado-Miravalles G, Pindado-Ortega C, PrietoBarrios M, Jimenez-Cauhe J. Comment on: Cutaneous manifestations in COVID-19: a first perspective. Safety concerns of clinical images and skin. J Eur Acad Dermatol Venereol. 2020 (in press). doi:10.1111/ jdv.16470.

22. Estébanez A, Pérez-Santiago L, Silva E, Guillen-Climent S, García-Vázquez A, Ramón MD. Cutaneous manifestations in COVID-19: a new contribution. J Eur Acad Dermatol Venereol. 2020 (in press). doi:10.1111/jdv.16474.

23. Morey-Olivé M, Espiau M, Mercadal-Hally M, Lera-Carballo E, García-Patos V. Cutaneous manifestations in the current pandemic of coronavirus infection disease (COVID 2019). An Pediatr. 2020 (in press) doi:10.1016/j.anpede.2020.04.002.

24. Gunawan C, Angela, Widysanto A. J Eur Acad Dermatol Venereol. 2020 May 9. doi: 10.1111/jdv.16622.

25. Gianotti R, Veraldi S, Recalcati S, et al. Cutaneous clinico-pathological findings in three COVID19-positive patients observed in the metropolitan area of Milan, Italy. Acta Derm Venereol. 2020;10.2340/00015555-3490.

26. Ahouach B, Harant S, Ullmer A, et al. Cutaneous lesions in a patient with COVID-19: are they related? Br J Dermatol. 2020 (in press). doi:10.1111/bjd.19168.

27. Zengarini C, Orioni G, Cascavilla A, et al. Histological pattern in Covid-19 induced viral rash [published online ahead of print, 2020 May 2]. J Eur Acad Dermatol Venereol. 2020;10.1111/ jdv.16569. doi:10.1111/jdv.16569.

28. Najarian DJ. Morbilliform exanthem associated with COVID-19. JAAD Case Rep. 2020. doi: 10.1016/j. jdcr.2020.04.015.

29. Ehsani AH, Nasimi M, Bigdelo Z. Pityriasis rosea as a cutaneous manifestation of COVID-19 infection. J Eur Acad Dermatol Venereol. 2020 (in press). doi:10.1111/jdv.16579.

30. Sanchez A, Sohier P, Benghanem S, et al. Digitate papulosquamous eruption associated with severe acute respiratory syndrome coronavirus 2 infection. JAMA Dermatol. 2020 (in press). doi:10.1001/jamadermatol.2020.1704.
31. Chang LY, Lu CY, Shao PL, et al. Viral infections associated with Kawasaki disease. J Formos Med Assoc. 2014;113:148-154. doi: 10.1016/j.jfma.2013.12.008.

32. Verdoni L, Mazza A, Gervasoni A, et al. An outbreak of severe Kawasaki-like disease at the Italian epicentre of the SARS-CoV-2 epidemic: an observational cohort study. Lancet. 2020 (in press). doi:10.1016/S0140-6736(20)31103-X.

33. Labé $P$, Ly A, Sin C, et al. Erythema multiforme and Kawasaki disease associated with COVID-19 infection in children. J Eur Acad Dermatol Venereol. 2020 (in press). doi:10.1111/ jdv.16666.

34. Rivera-Figueroa El, Santos R, Simpson S, Garg P. Incomplete Kawasaki Disease in a Child with Covid-19 [published online ahead of print, 2020 May 9]. Indian Pediatr. 2020;S097475591600179.

35. Jones VG, Mills M, Suarez D, et al. COVID-19 and Kawasaki Disease: Novel Virus and Novel Case. Hosp Pediatr. 2020 (in press). doi:10.1542/hpeds.2020-0123.

36. Jimenez-Cauhe J, Ortega-Quijano D, Carretero-Barrio I, et al. Erythema multiforme-like eruption in patients with COVID-19 infection: clinical and histological. findings Clin Exp Dermatol. 2020 (in press). doi:10.1111/ced.14281.

37. Torrelo A, Andina D, Santonja C, et al. Erythema multiforme-like lesions in children and COVID-19. Pediatr Dermatol. 2020 (in press). doi:10.1111/pde.14246.

38. Manalo IF, Smith MK, Cheeley J, Jacobs R. A dermatologic manifestation of COVID-19: transient livedo reticularis. J Am Acad Dermatol. 2020 (in press). doi: 10.1016/j. jaad.2020.04.018. 